\title{
Robert F. Heary and Todd J. Albert (eds): Spinal deformities- the essentials
}

\author{
2nd Edition, 2014, 438 pp, Hardback, 492 illustr., EUR (D) 99.99, US\$ 129.99, CHF \\ 140,00, ISBN (Americas): 978-1-60406-411-7
}

Pierre Kehr

Received: 15 December 2014/ Accepted: 28 December 2014/Published online: 31 January 2015

(C) Springer-Verlag France 2015

True bible of the vertebral deformities, this book is a work gathering 65 authors, in almost totality North Americans. These lesions considered a long time with fate, now are part of the great conquests of the modern orthopedic surgery.

The work considers the vertebral deformations under all the aspects: the historical development, validity of the different treatments, intraoperative neuromonitoring, anatomical criteria, the classification of the idiopathic scolioses, deformities in the sagittal plan and the coronal plan, the concept of fixity and flexibility, the natural history of the vertebral deformities, then the enormous part devoted to the treatments of the various deformities with detailed analysis of all the surgical techniques currently used that is for the scolioses, the hypercyphoses, the spondylolistheses, but also vertebral osteotomies, revision surgeries, to finish with the nonsurgical preventive measures and finally nonoperative treatments such braces.

Each chapter contains a rich bibliography, which is abundantly illustrated; finally, the work ends in a detailed index making it possible to reach quickly the different entries.

This book will have to be present in the library of all the surgeons and doctors implied in the treatment of the vertebral deformities.

Conflict of interest None.

P. Kehr $(\bowtie)$

Strasbourg, France

e-mail: pierre.kehr@gmail.com 